\title{
Depression, Anxiety and Stress among Students amidst COVID-19 Pandemic: A Cross-Sectional Study in Philippines
}

\author{
Joel Rey U. Acob ${ }^{1} \odot$, Hidayat Arifin ${ }^{2^{\star}} \oplus$, Yulis Setiya Dewi ${ }^{3} \oplus$ \\ ${ }^{1}$ College of Nursing, Visayas State University, Baybay City, Leyte, Philippines \\ ${ }^{2}$ Department of Medical Surgical Nursing, Faculty of Nursing, Universitas Padjadjaran, \\ Bandung, Indonesia \\ ${ }^{3}$ Department of Advanced Nursing, Faculty of Nursing, Universitas Airlangga, \\ Surabaya, Indonesia
}

Gopen access

\section{Jurnal Keperawatan Padjadjaran (JKP)}

Volume 9(2), 102-109 (C) The Author(s) 2021 http://dx.doi.org/10.24198/jkp. v9i2.1673

\section{Article Info}

Received : June 26, 2021 Revised : July 1, 2021 Accepted : July 12, 2021 Published : August 31, 2021

Corresponding author Hidayat Arifin Department of Medical Surgical Nursing, Faculty of Nursing, Universitas Padjadjaran, Bandung, Indonesia, Postal address: 45363 , Phone: 62 8113184433, E-mail: hidayat.arifin@unpad.ac.id

\section{Citation}

Acob, J. R. U., Arifin, H., \& Dewi, Y. S. (2021). Depression, Anxiety and Stress among Students amidst COVID-19 Pandemic: A Cross-Sectional Study in Philippines. Jurnal Keperawatan Padjadjaran, 9(2), 102-109. https://doi.org/10.24198/jkp. v9i2.1673

\section{Website}

http://jkp.fkep.unpad.ac.id/index. php/jkp

This is an Open Access article distributed under the terms of the Creative Commons Attribution-NonCommercial 4.0 International License.

E-ISSN: 2442-7276 P-ISSN: 2338-5324

\begin{abstract}
Background: COVID-19 considered as a global health crisis poses mental health problems among individual and specifics to students.

Purpose: This study aimed to determine the depression, anxiety, and stress levels among students amidst COVID-19 pandemic in Philippines.

Methods: A cross-sectional study was undertaken in Region 8, Eastern Visayas Philippines. A total of 311 tertiary respondents randomly selected both private and government owned higher education institutions. The data compilation was done using online questionnaires through Google Forms with validated version of the Stress, Anxiety and Depression Scales 21 (DASS21) is used to calculate students' level of stress, anxiety and, depression with their socio-demographic features

Results: We revealed that depression, anxiety and stress are instituted in $18.6 \%, 35.1 \%$ and $2.85 \%$ of students, respectively, amidst the COVID - 19 pandemics. The symptoms of disorders were moderate to extremely severe in $6.1 \%, 23.5 \%$, and $0.6 \%$ of the study sample, respectively. Age, gender, marital status and family history of illness are significantly different with age group 20 and below, females, singles, and families with no history of illness displaying high level of anxiety. Results also established an association between anxiety and family's monthly income and history of illness. The higher the monthly income and no presence of illness of families, the more anxious the person.

Conclusion: Finally, the variables used, explained only $1.5 \%$ depression, $3.4 \%$ anxiety and $1.4 \%$ stress in this time of COVID-19 outbreak. It is therefore recommended to essentially develop community-based mental health program for preventive purposes.
\end{abstract}

Keywords: anxiety; caring; COVID-19 pandemic; depression; nursing

\section{Introduction}

There is no doubt the world has recorded an unprecedented viral outbreak these days (Boccaletti et al., 2020; Lin et al., 2020). The new high-infectious and destructive coronavirus (Choi, 2020; Ivanov, 2020; Ivanov \& Dolgui, 2020 ) is confirmed to be COVID-19. This virus was first identified in China, Wuhan, in late 2019. It has spread around the world and has caused thousands of deaths and illnesses ( $\mathrm{H}$. Wang et al., 2009). As of 27 May 2020, 5.69 million confirmed cases and 355,575 deaths have already been reported worldwide. The number of confirmed cases has steadily increased. Without any type of medicine or Covid-19 immunization the disease has become a matter of concern More than one third (Kaplan \& Milstein, 2021) of the world's population is locked with limited movements to control the widespread of the virus. People should be kept away from social contact, wear masks, and regularly hand washing (Cheng et al., 2020).

The Philippines is like the rest of the world in lock-down (Sahu \& Kumar, 
Table 1. Socio-Demographic Characteristics of The Respondents $(n=311)$

\begin{tabular}{|c|c|c|c|}
\hline Category & & $\mathbf{n}$ & $\%$ \\
\hline \multirow{2}{*}{ Age } & $\leq 20$ years & 184 & 59.2 \\
\hline & $\geq 21$ years & 127 & 40.8 \\
\hline \multirow{2}{*}{ Gender } & Male & 69 & 22.2 \\
\hline & Female & 242 & 77.8 \\
\hline \multirow{2}{*}{ Marital status } & Single & 302 & 97.1 \\
\hline & Married & 9 & 2.9 \\
\hline \multirow{3}{*}{ Family monthly income } & $\leq 5000$ & 265 & 85.2 \\
\hline & $5000-15000$ & 41 & 13.2 \\
\hline & $\geq 15001$ & 4 & 1.3 \\
\hline \multirow{2}{*}{ Family history of IIIness } & Yes & 169 & 54.3 \\
\hline & No & 142 & 45.7 \\
\hline
\end{tabular}

2020). Its first confirmed case of COVID-19 was on March 7th, 2020. With recent increase of cases in the Philippines, various agencies issued a resolution on the management of the COVID-19 situation on 12 March 2020. It includes class suspension at all levels, prohibiting of mass gatherings, and community quarantine rules (Vallejo \& Ong, 2020).

There has been the apprehension of the population as a result of the advent of a new pandemic in which people have really had no previous contact with it. This led them to stay at home and leave only if needed (Buenaventura et al., 2020). Continuous restrictions are not easy to deal with and people with depressive symptoms, negative effects, cognitive loss, and disturbance of sleep patterns can develop under the required confinement (Avasthi \& Grover, 2018). The pandemic stress, anxiety, and depression follow well known behavioral reactions (Meng et al., 2020). The stress of any event that threatens our immune function can be defined as a state of emotional and physical distress. At the same time, anxiety is called fear of uncertainness, which is the normal response of the body to circumstances (Rehman et al., 2021). This fear leads to selfishness like panic buying, capitalist behaviour, xenophobia and belief in all social media news. The crisis occurs when there is the disbalanced and unintegrated culture in the Filipinos since the announcement of COVID-19 in the Philippines (Nicomedes \& Avila, 2020). Crisis is evident in Filipinos' actions. People are always ready to share their resources within the family, but are too reluctant to communicate them to others because their individual development needs to be secured.

Depression is known in everyday lives as a condition of disinterest. It is believed that people facing an unvaccinated pandemic will trigger fear making them nervous, worried and depressed. Given the growing global concerns about mental distress, have suggested appropriate psychological health measures throughout this pandemic (Xiang et al., 2020). In addition, recommendations on the public interest have been published by the WHO to tackle potential psychological problems. Now what is worrisome is the increase anxiety of the corona viral infection that culminates in people to commit suicide (Mamun et al., 2020). A study report during the initial phase of COVID-19 outbreak, Chinese citizens had a serious mental illness (anxiety, stress, depression) (C. Wang et al., 2020). Likewise, a further study conducted by Chinese people found mental illness (stress, anxiety, and depression) very widespread (Qiu et al., 2020).

Under normal circumstances, elevated rates of mental distress are typical for college students and downstream adverse academic effects (Granton, 2019). As a result of physical distancing behavior in the COVID-19 response, tertiary schools have switched to an online emergency learning system which is expected to further intensify student academic stress. Students may experience a reduced chance to study, additional pressure to learn independently, the abandonment of their everyday lives and potentially dropouts, as a result of direct impacts on these actions, on the basis of research on the impact of academic disruption on students (Grubic et al., 2020). As a result, the COVID-12 pandemic has created an unprecedented psychological burden, which urgently needs more assessment and immediate intervention, because academic stressors in people with elevated preexisting stress levels and the ability to rely on traditional coping strategies - like the families themselves, who can have increased stress.

Research also showed that one of the classes with higher psychological problems were students (C. Wang et al., 2020). Although teachers seek to do what they can to educate online students, the results are not ideal. The key argument is that it is still doubtful that websites will be widely used and that major changes to distant learning will have an overwhelmingly veto effect on the future of students. Adolescence is a critical stage in psychological well-being growth and maintenance to a healthy adult life. Anxiety, depression and stress can significantly impact the health and academic achievement of adolescents through emotional disorders. Simply put, in an international health emergency like the one we are now experiencing, it is necessary to investigate the psychological effect 


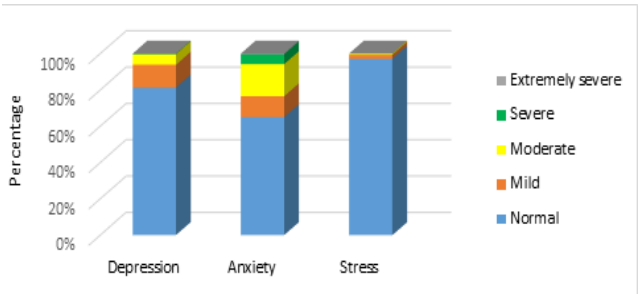

Figure 1. Respondents Level of Depression, Anxiety and Stress

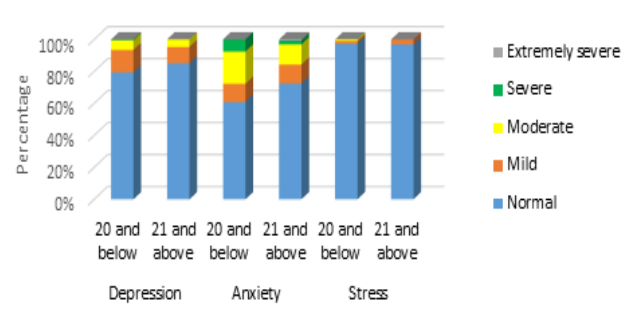

Figure 2. Depression, Anxiety, and Stress by Age

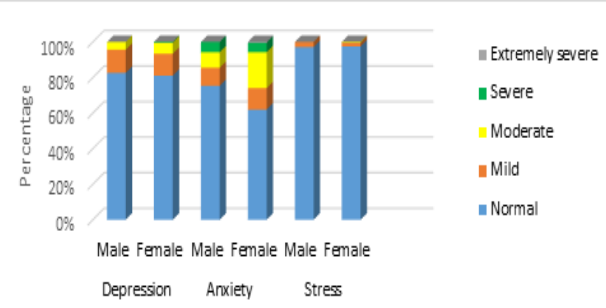

Figure 3. Depression, Anxiety, and Stress by Gender

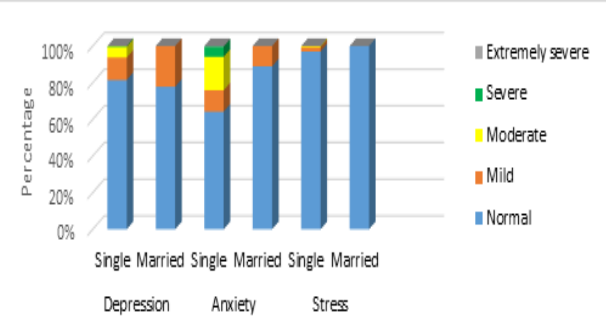

Figure 4. Depression, Anxiety, and Stress by marital Status

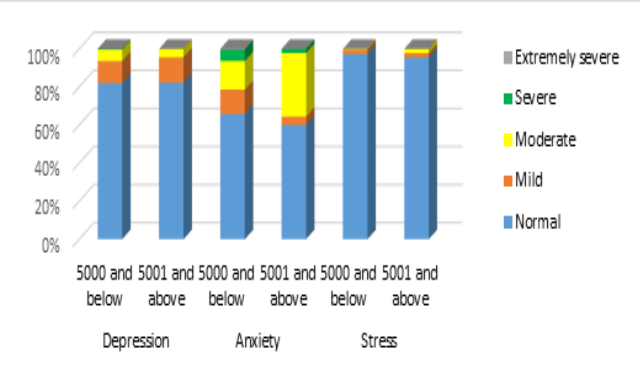

Figure 5. Depression, Anxiety, and Stress by Monthly Income

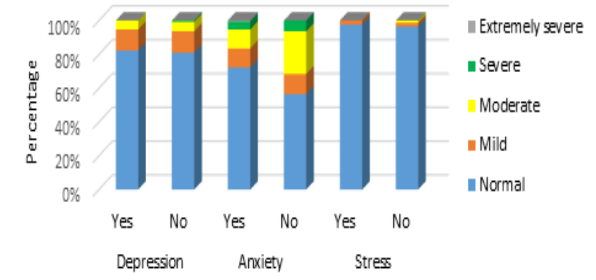

Figure 6. Depression, Anxiety, and Stress by Family History of IIIness

of the outbreak on individual populations in order to develop strategies to help reduce symptoms during crisis (Xiong et al., 2020). Thus the present study assessed depression, anxiety, and stress levels in a population of students at a particular epidemic to determine the psychological needs of dealing with the pandemic and potential causal factors.

\section{Methods}

\section{Study design}

A cross-sectional study was conducted in a sample of 311 tertiary students both in private and government owned higher education institutions in Leyte, Philippines, which were randomly selected.

\section{Instruments}

The study used the abbreviated version of the Stress, Anxiety and Depression Scales 21 (DASS21) (González-Rivera et al., 2020) and some socio-demographic information. The DASS consists of a 21-item questionnaire containing three self-reporting measures designed to measure the adverse emotional symptoms of depression, anxiety, and stress. The reliability of the instrument was 0.90 and the total Cronbach's alpha was 0.947 in this study. The item addressed using the 4-point Likert scales that ranged from 0 (A little time or none) to 3 (Most of the time) according to the occurrence and severity of symptoms during the last week. Every scale has seven items, and it measures its total score with the number of the items belonging to that scale. A higher score points to higher symptoms. Moreover, the DASS-21 contained cut-offs based on the results of various categories (standard, mild, moderate, serious and extremely severe).

\section{Data collection}

Data were collected from April through June 2020 following requirement of the university's mandate of output during the period of total lockdown. The data compilation was done using online questionnaires through the platform of Google Forms, and the respondents were recruited via social media. Moreover, respondents were told not to place any personal details on the scale to preserve hostility. The order of questionnaires presented were randomized. Students were recruited through the help of faculty members which redirected students to online survey. The survey took to complete for 
Table 2. T- test Analysis for DASS and Socio-demographic Characteristics of Students.

\begin{tabular}{|c|c|c|c|c|c|c|c|c|c|c|c|}
\hline \multirow{2}{*}{ Characteristics } & \multirow{2}{*}{ Category } & \multirow{2}{*}{$\mathbf{n}$} & \multicolumn{3}{|c|}{ Depression } & \multicolumn{3}{|c|}{ Anxiety } & \multicolumn{3}{|c|}{ Stress } \\
\hline & & & Mean & SD & $p$ & Mean & SD & $p$ & Mean & SD & $p$ \\
\hline \multirow{2}{*}{ Age } & $\leq 20$ years & 184 & 1.29 & 0.608 & \multirow{2}{*}{0.151} & 1.74 & 1.03 & \multirow{2}{*}{$0.028^{*}$} & 1.04 & 0.242 & \multirow{2}{*}{0.794} \\
\hline & $\geq 21$ years & 127 & 1.20 & 0.505 & & 1.50 & 0.881 & & 1.03 & 0.175 & \\
\hline \multirow{2}{*}{ Gender } & Male & 69 & 1.22 & 0.511 & \multirow{2}{*}{0.581} & 1.45 & 0.883 & \multirow{2}{*}{$0.043^{*}$} & 1.03 & 0.169 & \multirow{2}{*}{0.782} \\
\hline & Female & 242 & 1.26 & 0.585 & & 1.70 & 0.995 & & 1.04 & 0.229 & \\
\hline \multirow{2}{*}{ Marital status } & Single & 302 & 1.25 & 0.573 & \multirow{2}{*}{0.879} & 1.66 & 0.984 & \multirow{2}{*}{$0.001^{* *}$} & 1.04 & 0.220 & \multirow{2}{*}{0.309} \\
\hline & Married & 9 & 1.22 & 0.441 & & 1.11 & 0.333 & & 1.00 & 0.000 & \\
\hline \multirow{2}{*}{ Family income } & $\leq 5000$ & 266 & 1.25 & 0.575 & \multirow{2}{*}{0.840} & 1.62 & 0.972 & \multirow{2}{*}{0.329} & 1.03 & 0.192 & \multirow{2}{*}{0.473} \\
\hline & $\geq 5001$ & 45 & 1.27 & 0.539 & & 1.78 & 0.997 & & 1.07 & 0.330 & \\
\hline \multirow{2}{*}{$\begin{array}{l}\text { Family history of } \\
\text { Illness }\end{array}$} & Yes & 169 & 1.24 & 0.551 & \multirow{2}{*}{0.782} & 1.50 & 0.914 & \multirow{2}{*}{$0.005^{* *}$} & 1.02 & 0.152 & \multirow{2}{*}{0.323} \\
\hline & No & 142 & 1.26 & 0.592 & & 1.82 & 1.02 & & 1.05 & 0.275 & \\
\hline
\end{tabular}

${ }^{* *} p<0.01$ and ${ }^{*} p<0.05$

Table 3. Associations between Depression, Anxiety and Stress and Socio-demographic Variables.

\begin{tabular}{|c|c|c|c|c|c|c|c|}
\hline \multirow{2}{*}{ Category } & & \multicolumn{2}{|c|}{ Depression } & \multicolumn{2}{|c|}{ Anxiety } & \multicolumn{2}{|c|}{ Stress } \\
\hline & & $\mathbf{X}^{2}$ & $p$ & $\mathbf{X}^{2}$ & $p$ & $\mathbf{X}^{2}$ & $p$ \\
\hline \multirow{2}{*}{ Age } & $\leq 20$ & \multirow{2}{*}{2.38} & \multirow{2}{*}{0.498} & \multirow{2}{*}{7.90} & \multirow{2}{*}{0.095} & \multirow{2}{*}{2.15} & \multirow{2}{*}{0.341} \\
\hline & $\geq 21$ & & & & & & \\
\hline \multirow{2}{*}{ Gender } & Male & \multirow{2}{*}{0.638} & \multirow{2}{*}{0.888} & \multirow{2}{*}{5.99} & \multirow{2}{*}{0.200} & \multirow{2}{*}{0.736} & \multirow{2}{*}{0.692} \\
\hline & Female & & & & & & \\
\hline \multirow{2}{*}{ Marital status } & Single & \multirow{2}{*}{1.27} & \multirow{2}{*}{0.735} & \multirow{2}{*}{3.00} & \multirow{2}{*}{0.559} & \multirow{2}{*}{0.276} & \multirow{2}{*}{0.871} \\
\hline & Married & & & & & & \\
\hline \multirow{2}{*}{ Family monthly income } & $\leq 5000$ & \multirow{2}{*}{1.57} & \multirow{2}{*}{0.667} & \multirow{2}{*}{10.98} & \multirow{2}{*}{$0.027^{*}$} & \multirow{2}{*}{2.05} & \multirow{2}{*}{0.358} \\
\hline & $\geq 5001$ & & & & & & \\
\hline \multirow{2}{*}{ Family history of IIIness } & Yes & \multirow{2}{*}{1.21} & \multirow{2}{*}{0.751} & \multirow{2}{*}{12.91} & \multirow{2}{*}{$0.012^{*}$} & \multirow{2}{*}{2.41} & \multirow{2}{*}{0.299} \\
\hline & No & & & & & & \\
\hline
\end{tabular}

${ }^{* *} p<0.01$ and ${ }^{*} p<0.05$

about 15 minutes.

\section{Data analysis}

Data entry and analysis were done using SPSS version 22. Descriptive statistics such as frequency count, percentages, means and standard deviations were used. Data analysis was performed using t-test and Chi square test with a p-value of $<0.05$ was considered statistically significant.

\section{Ethical consideration}

This study has approved by Health Commission Ethics St. Paul University with number HA-2020-02.

\section{Results}

Majority of the respondents had a monthly family gross income of P5, 000 and below $(265,85.2 \%)$, predominantly females $(242,77.8 \%)$, belonged to the age group of 20 and below $(184,59.2 \%)$ and a family with history of illness $(169,54.3 \%)$ (Table 1$)$.

Figure 1 summarized the respondents' distribution according to the levels of severity indicated on the DAS scale. In this study, a total of
311 students took part. Depression, anxiety, and stress were found in $18.6 \%, 35.1 \%$, and $2.85 \%$ of the students. Moderate to extremely severe symptoms of disorder in $6.1 \%, 23.5 \%$, and $0.6 \%$ of the sample were shown, respectively. Moreover, in the midst of this pandemic threat, respondents believed that their mental health was in normal condition (81.4\%, depression; $65.0 \%$, anxiety; and $97.1 \%$, stress).

The respondents with symptoms of disorder were analysed for all the demographic characteristics. For younger respondents aged 20 and below, the rate of depression, anxiety, and stress was higher (12.6\%, $23.2 \%$, and $1.6 \%$ ) than for the older group aged 21 and above $(6.1 \%, 11.6 \%$ and $1.3 \%)$. The younger group were $5.7 \%$, and $11.6 \%$ more likely to have mild to extremely severe depression and anxiety than the older group, respectively. Conversely, older group was $0.44 \%$ more likely to have mild to moderate stress than the younger group (Figure 2). This was also indicated by the disorder mean scores of $6.02,6.58$, and 6.22 for the younger group and the older group 5.25, 5.61, and 5.50 for the older group, respectively. The mean score difference in anxiety was found to be significant $(p=.028)$ (Table 
2). This means that younger respondents were more anxious than older respondents. In addition, age does not relate to mental health disorder during this pandemic period $(p>0.05)$ (Table 3$)$.

Figure 3 reveals that the symptoms of disorder for females $(14.7 \%, 29.6 \%$, and $2.2 \%)$ was higher than for males $(3.9 \%, 5.5 \%$ and $0.70 \%)$. Females had $10.8 \%, 24.1 \%$ and $1.5 \%$ more symptoms of mild to extremely severe depression, anxiety and stress than males. This was also shown in the mean scores in disorder for females $(5.91,6.45$, and 6.06) and males (5.00, 5.28, and 5.45). The difference in mean scores in anxiety was found to be significant $(p=.043)$. This implies that females experienced more anxiety than males (Table 2 ). The results of the analysis also revealed that stress does not relate to gender (Table 3).

Depression, anxiety and stress was higher for singles $(18.0 \%, 34.8 \%$ and $2.9 \%)$ than married ones $(0.6 \%, 0.3 \%$ and $0.0 \%)$.). Singles were more depressed, anxious and under stress than married ones (Figure 4). However, the mean score in anxiety and stress for singles (6.22, and 5.95) were higher than married ones (5.11) yet, the mean score for depression was higher for married (6.22) than singles (5.69). The difference in mean scores of the respondents in anxiety was found to be significant $(p$ $=.001$ ). This indicates that singles displayed more symptoms of anxiety than married ones (Table 2). Further analysis found no association on marital status, in the mental health of the respondents, $p>$ 0.05 (Table 3).

Figure 5 illustrates the mental health disorder among respondents for families of different monthly income. Results showed that respondents from the lower monthly income families $(15.4 \%, 29.2 \%$ and $2.2 \%$ ) had the highest symptoms of the disorder as compared to other group (3.2\%, $5.7 \%$ and 0.70 On the other hand, the mean score in the depression, anxiety and stress for respondents with high monthly income families $(6.04,6.40$, and 6.38) were higher than respondents with low-income families (5.65, 6.15 and 5.85). The difference in mean scores of the disorder was not found to be significant ( $p$ $>$.05) (Table 2). Further, analysis also revealed that levels of anxiety was associated with family monthly income (X2 = 10.98; $p=0.027)$ but not for depression and stress. This means that the higher the families monthly income, the more anxious the person (Table 2).

Depression, anxiety and stress rates were higher among respondents with no history of family illness than those with families with history of illness. Respondents with no history of family illness were $1.3 \%, 21.8 \%$ and $1.2 \%$ more likely to have mild to extremely severe depression, anxiety, and stress than the other group, respectively (Figure 6). Similarly, the mean score in depression, anxiety and stress for respondents of families with no history of illness $(5.83,6.75$, and 6.17$)$ were higher than respondents of families with history of illness (5.61, 5.71 , and 5.72). The difference in mean scores of the respondents in anxiety was found to be significant ( $p$ $=.005$ ) (Table 2). This implies that those families with no history of illness were more likely to experience anxiety than their counterparts. Also, findings of the study have shown a significant association between history of family illness and anxiety (X2 = 12.91; $p=$ 0.012 ) but not for depression and stress (Table 2).

In summary, age gender, marital status and history of family illness are the characteristics that showed a significant difference in the level of anxiety. The younger age group 20 and under, females, singles and with no family history of illness displayed high level of anxiety than the other groups (Table 2). Moreover, family monthly income and history of illness are the variables associated with anxiety. Finally, the variables, which are used in regression explained only $1.5 \%$ of depression, 3.4 $\%$ of anxiety and $1.4 \%$ of stress (Table 3 ).

\section{Discussion}

The research is aimed at determining the depression, anxiety and stress level of the tertiary students enrolled at either private or public higher education institution in Leyte, Philippines. In the sample, moderate to extremely severe depression, anxiety, and stress levels were lower than in other studies (C. Wang et al., 2020). This is due to the subsequent reasons. First, data collection has been carried out before the Enhanced Community Quarantine (ECQ) and second, more information about the virus has been obtained since the first recorded case in the Philippines was one month after China, and three months later, the first local transmission in the country was confirmed. Such awareness may explain the lower rates of depression, anxiety and stress.

As far as age differences on depression, anxiety and stress were concerned, there were significant higher levels of depression, anxiety and stress in the 20 and below age bracket than in the 21 and above age bracket. These symptoms may have been due to the additional stress experienced by young students during the need to adapt to the new online educational environment, without faceto-face classes (Ivanov \& Dolgui, 2020). Thus, if these young people still find themselves vulnerable to mental disorders, education institutions must put in place prevention and intervention services to relieve tension (Boccaletti et al., 2020). This finding is similar to the study which found age group 1825 year age bracket had higher mean levels of stress, anxiety and depression followed by the age bracket 26-60 year bracket (Choi, 2020). However, it contradicts with previous findings that psychiatric disorder is more prevalent in adults aged 41-55 years compared to other adult age groups (Griffith et al., 2019).

The study also found that gender was not related to depression, anxiety and stress. The depression, anxiety and stress rate for females are significantly higher than for males. This is consistent 
with the previous findings that women during the pandemics are more prone to mental health (Acob, 2020a). Women may be more concerned with social and economic effects of the pandemic being the traditional caregiver in the family (Grubic et al., 2020). Similarly, according to a study of the American College Health Association (2019), using CIDI and MDQ inventories, it was found that $26.5 \%$ of women and $20.8 \%$ of men had psychiatric disorders, anxiety disorder (19.4\% vs $12 \%)$, and mood disorders. Other studies reported that common mental disorders are more common in women than in men in other countries (Chew et al., 2004). This difference can be attributed to socioeconomic disadvantage, cultural constraints, and violence. Women are more likely to express mental health problems than men. Evidence suggests the role of sex hormones in such gender differences.

In this study, age, gender, marital status, and history of family illness showed a significant difference in the level of anxiety. The younger group age 20 and below, females, single, and families with no history of illness were more anxious that those other groups. Moreover, family monthly income and history of illness were associated with the level of anxiety of the respondents. In general, the variables which are used explained only $1.5 \%$ of depression, $3.4 \%$ of anxiety and $1.4 \%$ of stress.

In short in this situation of unprecedented confinement for the Filipino students, it is highly important to deal with psychological factors. Most of the student-respondents exhibited a typical mental health disorder. This may mean that the students were still manifesting a strong and optimistic outlook in life in the midst of this pandemic problem. It doesn't automatically mean they don't experience any depression, anxiety or stress, but they have only decided to project hope and end this national disaster. This finding is contrary to previous study that college students encountered amplified negative emotions as several universities agreed to cancel face-to-face classes and relocate students in response to the increasing COVID-19 concerns (Choi, 2020). The same findings contradicted the result of this study in which college students felt uncomfortable due to confusion and sudden end of classes, in addition to the anxiety of closing schools. As more colleges move into distant learning after the spring break, due to the change in academic routine some students experienced poor mental health. Therefore, disruptions of their tasks and activities putting a risk in their program of study, postponed completion and hinder ability to find a job, consequently fuel insecurity among college students (H. Wang et al., 2009).

The same idea suggested that employment, education and gender affected signs of anxiety and depression that developed through this pandemic. Highlighted depressive disorders and anxiety are more usual in females, and it is expected that females will be more affected during pandemics (Acob, 2020b).

\section{Limitations}

While the work has made a major contribution to the psychological effects in COVID-19 and can be used by government, school administrators or other organizations, the study still shows some limitations. The survey was conducted online and is only available for students with internet access and excludes large parts of the population from participating.

\section{Conclusion}

In conclusion, it was found that students had mild to moderate levels of stress; mild to severe levels of depression and anxiety while most of them has normal levels of depression and stress. The majority of students do not suffer from stress; however there was a significant association between gender and the presence of stress levels. Finally, the students do not suffer from stress and also no associations were found regarding age, sex, marital status, and family monthly income. Moreover, it is necessary to develop community-based mental health programs. Further studies must be conducted on larger sample size and by selecting more sample in groups and include other possible factors such as social media, regular stress, and social skills that could also have a main effect rates of depression, anxiety and stress.

\section{Acknowledgement}

The authors would like to thank all the participants for their cooperation and all the school authorities in giving permission to conduct the study.

\section{Conflict of interest}

The author(s) declared no potential conflicts of interest with respect to the research, authorship, and/or publication of this article.

\section{Funding}

The author(s) received no financial support for the research, authorship, and/or publication of this article.

\section{References}

Acob, J. R. U. (2020a). Nursing the nursed: Addressing COVID-19 pandemic crisis in the cuen theory perspective. Belitung Nursing Journal, 6(2), 59-61. https://doi.org/10.33546/ bnj. 1103

Acob, J. R. U. (2020b). Appreciating positivity of COVID-19. Belitung Nursing Journal, 6(6), 226-228. https://doi.org/10.33546/bnj.1214

Avasthi, A., \& Grover, S. (2018). Clinical practice guidelines for management of depression in Elderly. Indian Journal of Psychiatry, 60(3), S341-S362. 5545.224474

Boccaletti, S., Ditto, W., Mindlin, G., \& Atangana, A. (2020). Modeling and forecasting of epidemic spreading: The case of COVID-19 and beyond. 
Chaos, Solitons \& Fractals, 135. https://doi. org/10.1016/j.chaos.2020.109794

Buenaventura, R. D., Ho, J. B., \& Lapid, M. I. (2020). COVID-19 and mental health of older adults in the Philippines: A perspective from a developing country. International Psychogeriatrics, 32(10), 1129-1133. https:// doi.org/10.1017/S1041610220000757

Cheng, K. K., Lam, T. H., \& Leung, C. C. (2020). Wearing face masks in the community during the COVID-19 pandemic: Altruism and solidarity. The Lancet, 399(10336), 39-40. https://doi. org/10.1016/S0140-6736(20)30918-1

Chew, D. S. H., Choi, K. P., Heidner, H., \& Leung, M.-Y. (2004). Palindromes in SARS and other Coronaviruses. INFORMS Journal on Computing, 16(4), 331-340. https://doi. org/10.1287/ijoc.1040.0087

Choi, T.-M. (2020). Innovative "Bring-Service-NearYour-Home" operations under Corona-Virus (COVID-19/SARS-CoV-2) outbreak: Can logistics become the Messiah? Transportation Research Part E. Logistics and Transportation Review, $140 . \quad$ https://doi.org/10.1016/j. tre.2020.101961

González-Rivera, J. A., Pagán-Torres, O. M., \& Pérez-Torres, E. M. (2020). Depression, anxiety and stress scales (DASS-21): Construct validity problem in Hispanics. European Journal of Investigation in Health, Psychology and Education, 10(1), 375-389. https://doi.org/10.3390/ejihpe10010028

Granton, J. (2019). American college health association: National college health assessment II: Reference group executive summary spring 2019. Canadian Journal of Respiratory, Critical Care, and Sleep Medicine, 3(2), 63-64. https://doi.org/10.1080/24745332 .2019 .1620558

Griffith, D. A., Boehmke, B., Bradley, R. V., Hazen, B. T., \& Johnson, A. W. (2019). Embedded analytics: improving decision support for humanitarian logistics operations. Annals of Operations Research, 283(1-2), 247-265. https://doi.org/10.1007/s10479-017-2607-z

Grubic, N., Badovinac, S., \& Johri, A. M. (2020). Student mental health in the midst of the COVID-19 pandemic: A call for further research and immediate solutions. International Journal of Social Psychiatry, 66(5), 517-518. https:// doi.org/10.1177/0020764020925108

Ivanov, D. (2020). Predicting the impacts of epidemic outbreaks on global supply chains: $A$ simulation-based analysis on the coronavirus outbreak (COVID-19/SARS-CoV-2) case. Transportation Research Part E: Logistics and Transportation Review, 136, 101922. https:// doi.org/10.1016/j.tre.2020.101922

Ivanov, D., \& Dolgui, A. (2020). Viability of intertwined supply networks: extending the supply chain resilience angles towards survivability. A position paper motivated by COVID-19 outbreak. International Journal of Production Research, 58(10), 2904-2915. https://doi.org/ 10.1080/00207543.2020.1750727

Kaplan, R. M., \& Milstein, A. (2021). Influence of a COVID-19 vaccine's effectiveness and safety profile on vaccination acceptance. Proceedings of the National Academy of Sciences, 118(10). https://doi.org/10.1073/pnas.2021726118

Lin, Q., Zhao, S., Gao, D., Lou, Y., Yang, S., Musa, S. S., Wang, M. H., Cai, Y., Wang, W., Yang, L., \& He, D. (2020). A conceptual model for the coronavirus disease 2019 (COVID-19) outbreak in Wuhan, China with individual reaction and governmental action. International Journal of Infectious Diseases, 93, 211-216. https://doi.org/10.1016/j.ijid.2020.02.058

Mamun, M. A., Syed, N. K., \& Griffiths, M. D. (2020). Indian celebrity suicides before and during the COVID-19 pandemic and their associated risk factors: Evidence from media reports. Journal of Psychiatric Research, 131, 177-179. https:// doi.org/10.1016/j.jpsychires.2020.09.002

Meng, L., Hua, F., \& Bian, Z. (2020). Coronavirus Disease 2019 (COVID-19): Emerging and future challenges for dental and oral medicine. Journal of Dental Research, 99(5), 481-487. https://doi.org/10.1177/0022034520914246

Nicomedes, C. J. C., \& Avila, R. M. A. (2020). An analysis on the panic during COVID-19 pandemic through an online form. Journal of Affective Disorders, 276, 14-22. https://doi. org/10.1016/j.jad.2020.06.046

Qiu, J., Shen, B., Zhao, M., Wang, Z., Xie, B., \& Xu, Y. (2020). A nationwide survey of psychological distress among Chinese people in the COVID-19 epidemic: implications and policy recommendations. General Psychiatry, 33(2), e100213. https://doi.org/10.1136/ gpsych-2020-100213

Rehman, U., Shahnawaz, M. G., Khan, N. H., Kharshiing, K. D., Khursheed, M., Gupta, K., Kashyap, D., \& Uniyal, R. (2021). Depression, anxiety and stress among indians in times of COVID-19 lockdown. Community Mental Health Journal, 57(1), 42-48. https://doi. org/10.1007/s10597-020-00664-x

Sahu, K., \& Kumar, R. (2020). Preventive and treatment strategies of COVID-19: From community to clinical trials. Journal of Family Medicine and Primary Care, 9(5), 2149-2157. https://doi.org/10.4103/jfmpc.jfmpc_728_20

Vallejo, B. M., \& Ong, R. A. C. (2020). Policy responses and government science advice for the COVID 19 pandemic in the Philippines: January to April 2020. Progress in Disaster Science, $7 . \quad$ https://doi.org/10.1016/j. pdisas.2020.100115

Wang, C., Pan, R., Wan, X., Tan, Y., Xu, L., Ho, C. S., \& Ho, R. C. (2020). Immediate psychological responses and associated factors during the Initial stage of the 2019 Coronavirus Disease (COVID-19) epidemic among the general 
Depression, Anxiety and Stress among Students

population in China. International Journal of Environmental Research and Public Health, 17(5). https://doi.org/10.3390/ijerph17051729

Wang, H., Wang, X., \& Zeng, A. Z. (2009). Optimal material distribution decisions based on epidemic diffusion rule and stochastic latent period for emergency rescue. International
Journal of Mathematics in Operational Research, 1(1/2), 76. https://doi.org/10.1504/ IJMOR.2009.022876

Xiang, Y.-T., Jin, Y., \& Cheung, T. (2020). Joint international collaboration to combat mental health challenges during the Coronavirus Disease 2019 pandemic. JAMA Psychiatry, 77(10), $\quad 989 . \quad$ https://doi.org/10.1001/ jamapsychiatry.2020.1057

Xiong, J., Lipsitz, O., Nasri, F., Lui, L. M. W., Gill, H., Phan, L., Chen-Li, D., lacobucci, M., Ho, R., Majeed, A., \& Mclntyre, R. S. (2020). Impact of COVID-19 pandemic on mental health in the general population: A systematic review. Journal of Affective Disorders, 277, 55-64. https://doi.org/10.1016/j.jad.2020.08.001 